\title{
THERMOMAGNETIC INVESTIGATION OF TEMPERING OF QUENCHED 0.75 PER CENT CARBON STEEL
}

\author{
By George A. Ellinger
}

ABSTRACT

Previous investigators have shown that martensite and retained austenite are present as constituents of quenched carbon steels. A study of the decomposition of these constituents in water quenched 0.75 per cent carbon steel has been made by means of thermomagnetic analysis. An astatic magnetometer was used to show changes in magnetization of specimens at various temperatures and these magnetization changes have been interpreted in the light of constitutional changes in the steel. Immediately upon the application of heat, an increase in magnetization took place, which is believed to represent stress release, caused by the precipitation of carbon from the supersaturated solid solution of carbon in alpha iron. The degree of tempering is believed to be dependent upon temperature and time, the first stage being completed at $200^{\circ} \mathrm{C}$. in about six and one-half hours. The precipitated carbon is believed to combine with iron in the range between $200^{\circ}$ and $300^{\circ} \mathrm{C}$. to form iron carbide. This combination is progressive with time, being completed at $300^{\circ} \mathrm{C}$. in about one hour. From $300^{\circ}$ to $700^{\circ} \mathrm{C}$. no further magnetic changes were noted upon holding at constant temperatures, consequently no further constitutional changes were believed to take place in this range, but the carbide apparently coagulated to form larger and larger particles. An increase in magnetization at about $235^{\circ} \mathrm{C}$. was believed to indicate the decomposition of austenite, the decomposition being completed in about 45 minutes at that temperature.

\section{CONTENTS}

Page

I. Introduction

II. Previous investigations

III. General considerations

IV. Method and material. 444

1. Apparatus. 444

2. Specimens and treatment. 444

V. Observations and results...

VI. Summary . .

VII. Acknowledgment.

\section{INTRODUCTION}

The decomposition or tempering of martensite is of great importance to the metallurgist interested in the heat treatment of steel. Various methods of observation have been used in studying this phenomenon, such as microscopic analysis, $\mathrm{X}$-ray analysis, dilatometric measurements, thermal analysis, electrical resistance measurements, and thermomagnetic analysis. The first five methods are well known and need no explanation.

Thermomagnetic analysis reveals, in terms of changes in magnetic properties upon heating or cooling, certain constitutional transformations which are difficult to follow by means of most of the other methods. It was thought, therefore, that it might be possible to obtain by this method a fairly complete picture of the decomposition of martensite, taking place upon the tempering of quenched steels. 
The condition of the carbon in the quenched state and that occurring as the tempering process proceeds is of considerable importance, and is not definitely known. Any light that can be thrown on this question, therefore, should aid materially in the solution of this problem. It has been very well established by several investigators that cementite undergoes a magnetic transformation, similar to the $A_{2}$ transformation in iron, at a temperature of approximately $215^{\circ} \mathrm{C}$. This transformation, known as the $A_{0}$ transformation, is clearly shown by curves obtained by thermomagnetic analysis and, therefore, serves as a valuable criterion in the interpretation of results. It is of utmost importance to distinguish clearly between variations in magnetization which are due to actual structural changes and those which may be of purely magnetic origin.

This paper is a report on one phase of a more comprehensive study of quenched and tempered steels by means of thermomagnetic analysis with the cooperation of R. L. Sanford, chief of the magnetic measurements section of the National Bureau of Standards.

\section{PREVIOUS INVESTIGATION}

Honda ${ }^{1}$ has concluded that cementite is in solid solution in quenched steels and that upon gradual rise of tempering temperature to $400^{\circ} \mathrm{C}$., the carbide is precipitated.

Ishiwara ${ }^{2}$ investigated the tempering of 0.94 per cent carbon steel and found an increase in magnetization at $130^{\circ} \mathrm{C}$., which he attributed to the tempering of martensite to troostite.

Saito ${ }^{3}$ investigated quenched and tempered steels and concluded that upon tempering a quenched steel at $300^{\circ}$ C., cementite was first set free, but owing to the extremely fine particle size, it decomposed rapidly into iron and carbon, which subsequently recombined to form cementite.

Heyn and Bauer ${ }^{4}$ determined the solubility in acids, of steels treated in various ways. Quenched steel, tempered at $400^{\circ} \mathrm{C}$., was the most soluble, the rate of solubility decreasing in either direction, toward martensite on one side and pearlite on the other. Troostitic specimens left no residue of carbide, but a residue of carbon containing little or no iron. The authors suggested that some substance which they called " $X$ " separated from martensite upon tempering up to $400^{\circ} \mathrm{C}$. This substance differed greatly from cementite in its reactions with hydrochloric and sulphuric acids.

Maurer ${ }^{5}$ investigated the magnetic properties of various steels and found results similar to those of Heyn and Bauer.

Dearden and Benedicks ${ }^{6}$ investigated various annealed and quenched steels by means of thermomagnetic analysis. They found a slight increase in magnetization, for annealed steels, at about $130^{\circ}$ C. and a point of decreased magnetization, at $210^{\circ}$ C. Steels

1 Kotaro Honda, On the Magnetic Investigation of the States of Cementite in Annealed and Quenched Carbon Steels, Scl. Repts., Tohoku Imporial Univ., Sendai, 6, p. 149; 1917.

2 Torajiro Ishiwara, On the Magnetic Analysis of Carbides Found in Different Kinds of Steel, Sci. Repts., Tohoku Imperial Univ., Sendai, 6, p. 285; 1917.

3 Seizo Saito, On the Stato of Carbon Steels, Quenched and Tempered, Sci. Repts., Tohoki Imperial Univ., Sendai, 9, p. 281; 1920.

4 E. Heyn and O. Bauer, Influence of the Treatment on the Solubility of Stoels in Sulphuric. Acid, J. Iron and Steel Inst., 79, p. 109; 1909.

s E. Maurer, Recherches sur la trempe et le revenu du fer et de l'Acier, Revue de Metallurgie, 5, p. 711; 1908.

- W. H. Dearden and C. Benedicks, Magnetic Changes in Iron and Steel Below $400^{\circ}$ O., J. Iron and Steel Inst. 113, p. 393; 1926. 
quenched from $910^{\circ} \mathrm{C}$. showed weak changes in magnetization at $120^{\circ}$ and $260^{\circ} \mathrm{C}$.

Duell $^{7}$ investigated the magnetic properties of carbon steels by means of a ballistic galvanometer method. Upon heating quenched specimens to high temperature, he found a discontinuous drop in magnetism at $300^{\circ} \mathrm{C}$., explaining this as "possibly being due to the formation of iron carbide, the carbon of which was finely divided throughout the mass." Duell found no evidence which would indicate the formation of troostite from austenite, and concluded that austenite tempers at a "lower temperature and is probably not a very abrupt change." In this investigation a rather low magnetizing force of the order of 7.6 gilberts per centimeter was used.

Enlund ${ }^{8}$ made electrical resistance measurements on eight carbon steels, and found that martensite started to temper to troostite at $100^{\circ} \mathrm{C}$. and that the tranformation was most marked at $110^{\circ} \mathrm{C}$., while austenite tempered at about $260^{\circ} \mathrm{C}$. to troostite.

Results reported recently by Sefing ${ }^{9}$ on the energy evolved during solution of quenched and tempered steel, obtained by means of an adiabatic calorimeter are in accord with the results of the present investigation. The maximum evolution of heat was obtained with specimens tempered at $150^{\circ} \mathrm{C}$. and a second maximum was obtained with specimens previously tempered at $350^{\circ} \mathrm{C}$.

\section{GENERAL CONSIDERATIONS}

As pointed out in the introduction, it is of great importance, in the interpretation of the results of thermomagnetic analysis, to distinguish clearly between changes due to constitutional transformations and those due to normal magnetic origin.

The normal magnetization curve consists of three more or less distinct stages. In the first stage, there is a considerable degree of magnetic stability, but the magnitudes to be measured are small and the curve is quite sentitive to the effects of previous magnetic history.

In the second stage, the curve is relatively steep and represents a region of magnetic instability. In this region many effects, such as strain, temperature, etc., have their maximum influence on the magnetization. It is difficult, therefore, to interpret data obtained in the second stage of magnetization with any degree of certainty. This point is often overlooked in researches in the field of magnetic analysis.

The third stage of magnetization represents the region of greatest magnetic stability in which differentiation between the effects of various influences can be made more easily. It is generally preferable to work in the third stage of magnetization.

For the type of steel under investigation it is generally necessary to apply a magnetizing force of at least 100 gilberts per centimeter to bring the material into the third stage. In the present investigation, the value of the applied magnetizing force was always 277 gilberts per centimeter. For the dimensional ratio of the specimens

${ }^{7}$ Clifford C. Duell, Magnetic Investigations of Carbon Steel, Transactions, Am. Soc. Steel Treating, 15, p. $630 ; 1929$.

B. D. Enlund, On the Structure of Quenched Carbon Steels, J. Iron and Stoel Inst., 111, p 305; 1925.

- Frederick G. Sefing, Thermodynamics of a Heat Treated Steel, Bull. Michigan Eng. Expt. Station, East Lansing, Mich., 6, No. 7; May 1931. 
used, the demagnetizing factor was of such a value that the effective magnetizing force was never less than 150 gilberts per centimeter.

The inflection in the magnetization-temperature curve in the neighborhood of $200^{\circ} \mathrm{C}$. has been the subject of study by various investigators, notably by Honda and his associates, ${ }^{10}{ }^{11}$ and is generally agreed to be due to the magnetic transformation of cementite, $\mathrm{Fe}_{3} \mathrm{C}$. The temperature at which this change is complete on heating and begins on cooling has been established by Honda, as $215^{\circ} \mathrm{C}$. The $A_{0}$ transformation in pearlitic steels, increases in intensity as the carbon content increases. The minimum carbon content, at which the transformation will be found is not definitely known. However, from unpublished records of the magnetic measurements section of the National Bureau of Standards it has been found that annealed steel containing 0.14 per cent carbon shows a very definite $A_{0}$ transformation, the intensity of which is approximately 3 per cent.

It is conceivable that when cementite is present as one of the constituents of steel there might be conditions, such as the form and distribution of the carbide, or strain effects, etc., which would modify the transformation temperature just as other transformation points are altered by various alloying elements. There is some evidence in the results here reported that this is the case.

\section{METHOD AND MATERIAL}

\section{APPARATUS}

The magnetometer method of thermomagnetic analysis was adopted as being the most suitable for the present investigation. 'By this method, changes in magnetization at a constant value of applied magnetizing force can be continuously observed as the heating or cooling progresses. The degree of magnetization is indicated by the deflection of an astatic magnetometer, so adjusted as to be practically free from the influence of outside magnetic disturbances. The apparatus used was a slightly modified form of that previously described by Sanford. ${ }^{12}$

\section{SPECIMENS AND TREATMENT}

The material studied was a basic open-hearth steel of the following composition:

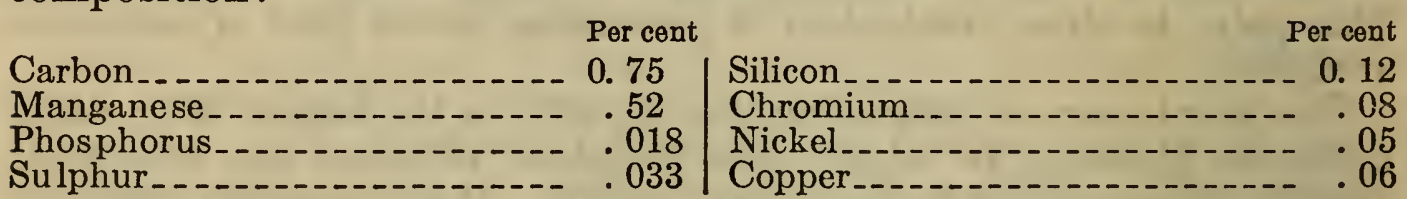

The specimens were $10 \mathrm{~cm}$ in length and $6 \mathrm{~mm}$ in diameter having a length to diameter ratio of 16.7 , so that the self-demagnetizing effect of the specimens was not excessive. The specimens were normalized after machining to relieve any residual strains which may have been present.

10 Kotaro Honda and Hiromu Takagi, On the Magnetic Transformation of Cementite, Sci. Repts., Tohoku Imperial Univ., Sendai, 4, p. 161; 1915.

11 Kotaro Honda and Takejiro Murakami, On the Thermomagnetic Properties of the Carbides Found in Steel, Sci. Rpts., Tohoku Imperial Univ., Sendai, 6, p. 23; 1917.

12 R. L. Sanford, Apparatus for Thermomagnetic Analysis, B. S. Jour. Research, 2 (RP50), p. $659 ; 1929$. 
The normalized specimens were packed in carburizing boxes containing fine silica sand and charcoal and heated to $825^{\circ} \mathrm{C}$. in an automatically controlled electric muffle furnace. After holding at temperature for 30 minutes, certain specimens were hardened by quenching in a large volume of water at approximately $20^{\circ} \mathrm{C}$. Other specimens were allowed to cool in the furnace.

Quenched specimens were placed in the apparatus immediately and normal magnetization-temperature curves taken, using a heating and cooling rate of approximately $2^{\circ} \mathrm{C}$. per minute. From these curves, temperatures were selected at which to temper other freshly quenched specimens. These specimens were then placed in the apparatus, heated to the various selected temperatures, and held until it was certain that all magnetic changes had been completed. The specimens were then cooled slowly to room temperature, observations being made during both heating and cooling.

\section{OBSERVATIONS AND RESULTS}

Magnetization-temperature curves for electrolytic iron and for annealed and quenched 0.75 per cent carbon steel are shown in Figure 1. Magnetization is plotted in per cent, 100 per cent representing the magnetization at room temperature at the start of a run.

Electrolytic iron showed no $A_{0}$ transformation, the magnetization remaining constant over the range of temperatures investigated.

The annealed steel showed a very definite pearlitic $A_{0}$ transformation ending at about $215^{\circ} \mathrm{C}$. on heating and commencing at the same temperature on cooling. There was some hysteresis, probably thermal, as is indicated by the difference in percentage magnetization between the heating and cooling curves at $400^{\circ} \mathrm{C}$. This steel was heated above the critical range and cooled, only those portions of the curves being shown which lay between $0^{\circ}$ and $400^{\circ} \mathrm{C}$., this being the range of temperatures in which the primary interest of the investigation lay. It was found that between $400^{\circ}$ and $700^{\circ}$ C. no magnetization change with time took place upon holding at various temperatures in this range.

The magnetization-temperature curves, as determined on a specimen freshly quenched in cold water from $825^{\circ} \mathrm{C}$. are also shown in Figure 1. There is a small increase in magnetization up to approximately $125^{\circ} \mathrm{C}$, after which the increase is more rapid as heating progresses. At approximately $250^{\circ} \mathrm{C}$. another increase in rate takes place, the curve reaching a maximum at about $290^{\circ} \mathrm{C}$., after which the magnetization rapidly decreases to $400^{\circ} \mathrm{C}$. Upon cooling, the $A_{0}$ transformation, which is entirely lacking on the heating curve, appears. As in the case of the annealed steel, this specimen was heated above the critical range and cooled, but only those parts of the curves between $0^{\circ}$ and $400^{\circ} \mathrm{C}$. are shown.

The lack of an $A_{0}$ transformation could be due to three things--the masking effect of stress release, the presence of carbide in sufficiently finely divided particles so that the transformation might be suppressed, or to the absence of carbide. In order to determine which of these might have been responsible in this case, several investigations were made.

Highly stressed steel shows no $A_{0}$ transformation. This is very well shown in cold-drawn steel wire. Martensite, as is well known, 
is in a very highly stressed condition and could mask the $A^{\circ}$ transformation, even if carbide were present.

In order to determine whether the absence of the $A_{0}$ transformation was due to the masking effect of stress release, a freshly quenched specimen was heated to $200^{\circ} \mathrm{C}$. and held until all change in magnetization was complete. The specimen was then cooled with the results shown in curve 1, Figure 2. Curve 1, Figure 3, shows the change

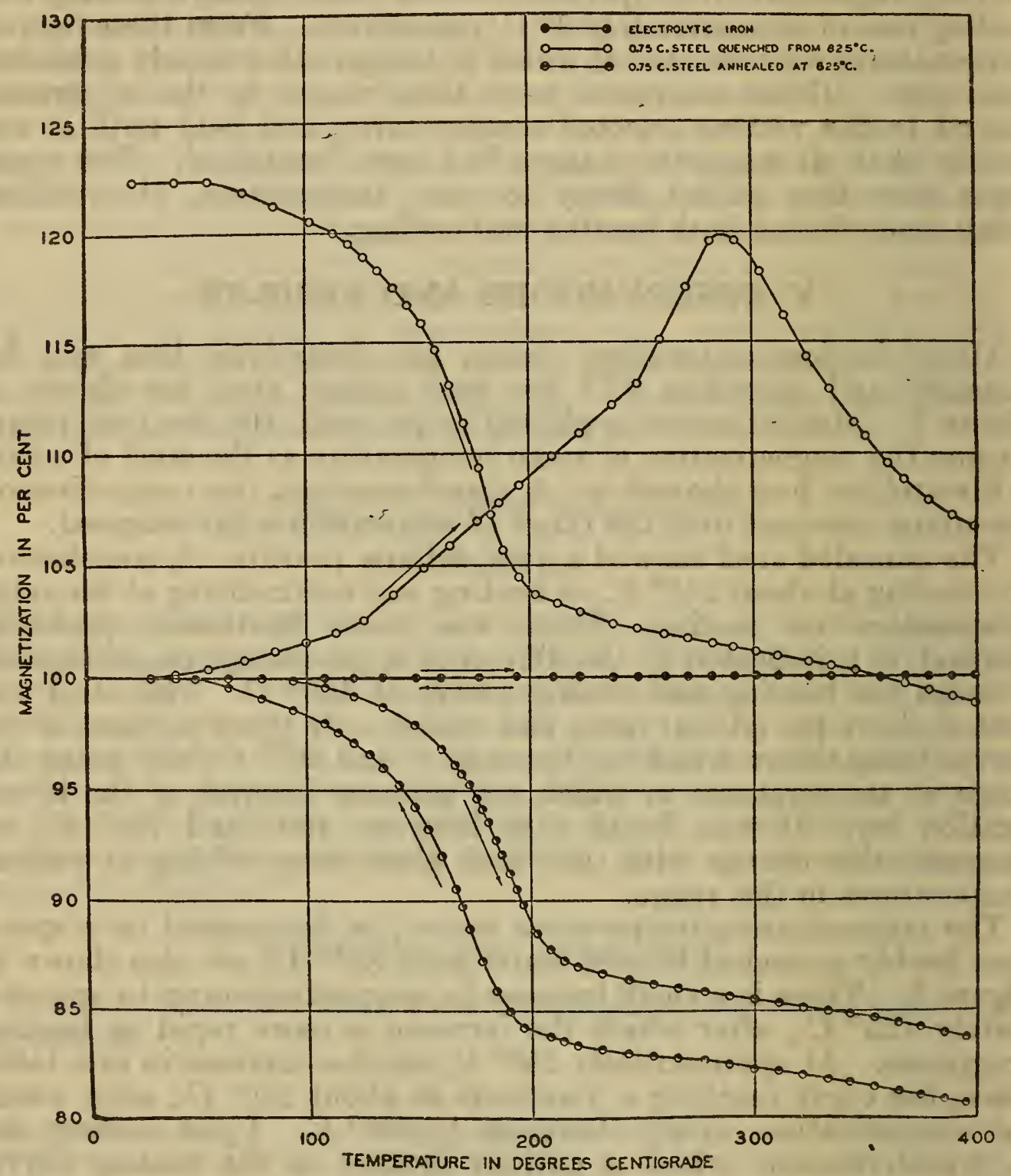

FIGURE 1.-Magnetization-temperature curves for annealed electrolytic iron, annealed steel, and quenched steel containing 0.75 per cent carbon

of magnetization with time at constant temperature and represents the portion $a-b$ as indicated on curve 1 of Figure 2. Heating and cooling are indicated on the curves by directional arrows.

At $200^{\circ} \mathrm{C}$. the magnetization gradually increased for six and onehalf hours, after which no further change took place at that temperature. There was no change in magnetization upon cooling to room temperature, the curve being a straight line. Upon reheating, after cooling to room temperature, the magnetization remained con- 
stant until a temperature of $235^{\circ} \mathrm{C}$. was reached, shown in curve 2, Figure 2. This indicates that no $A_{0}$ transformation had taken place,
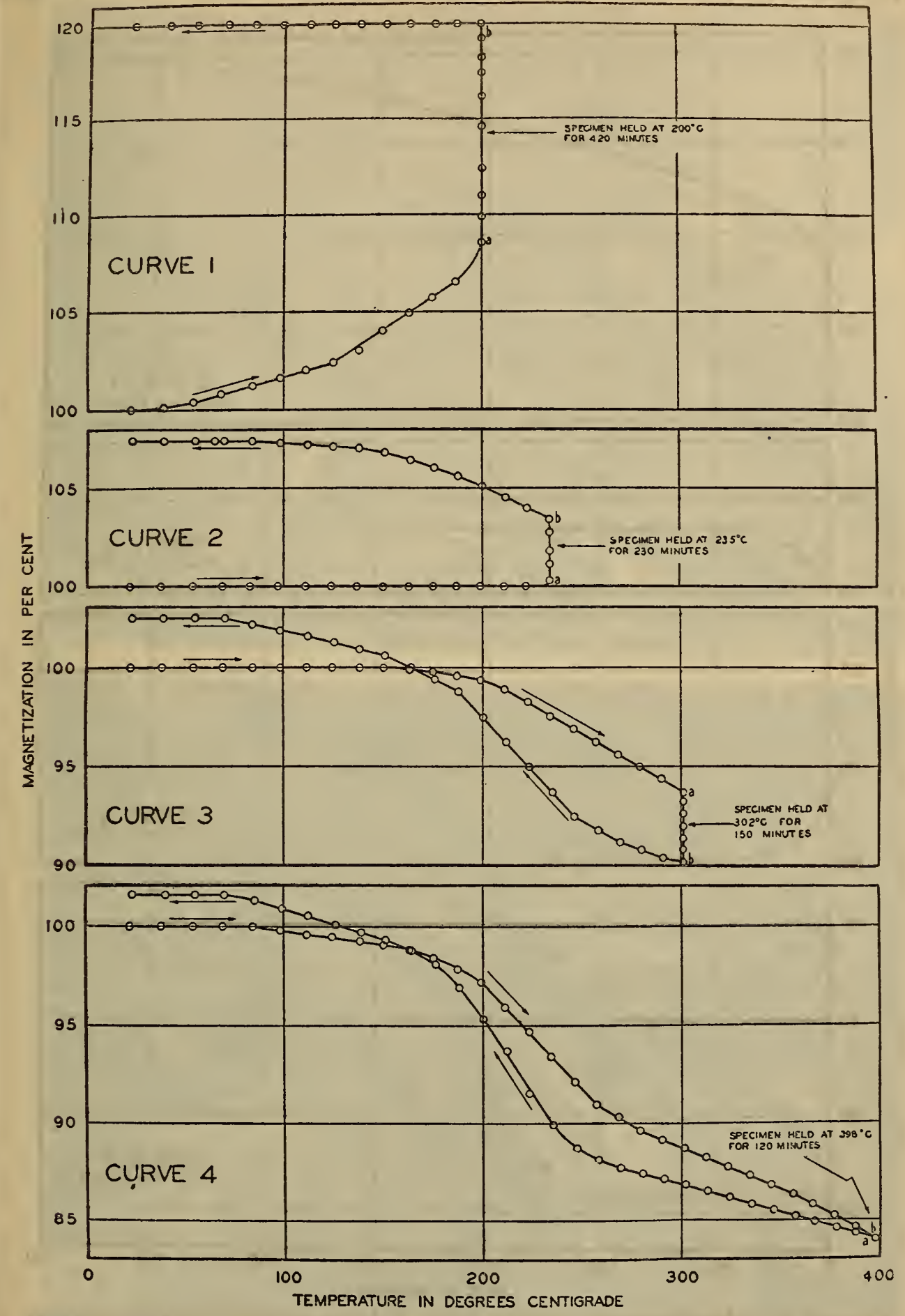

FIGURE 2.-Magnetization change with temperature in heating a quenched 0.75 per cent carbon sieel to various temperatures

The portion $a-b$ of each curve represents the change at the tempering temperature. Heating and cooling curves are indicated by directional arrows

and that the increase in magnetization shown upon the first heating of the quenched steel to $200^{\circ} \mathrm{C}$. was probably due to the release of stresses and did not mask an $A_{0}$ transformation. 
To determine whether or not the presence of carbide in very finely dispersed particles would fail to show an $A_{0}$ transformation, a detailed investigation of the effect of carbide size was made. The results
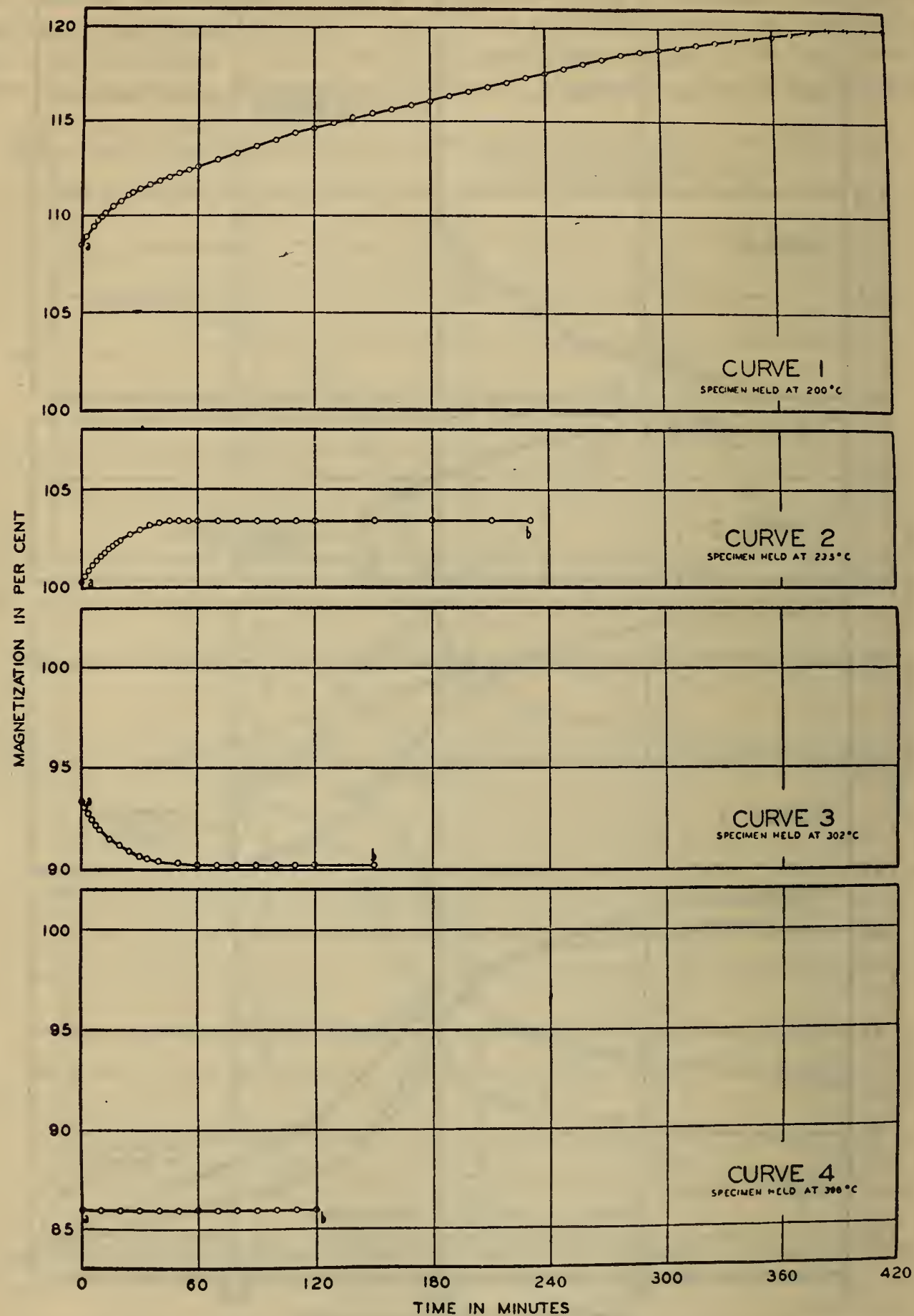

FIGURE 3.-Magnetization change upon holding at constant temperatures

These curves represent the portion $a-b$ of the corresponding curves shown in Figure 2

have been reported in another publication. ${ }^{13}$ It was. found that the intensity of the transformation increased as the particle size decreased. Specimens in which the carbides were so fine as to be barely resolvable

$13 \mathrm{R}$. L. Sanford and G. A. Ellinger, Thermomagnetic Analysis and the $A_{0}$ Transformation in $0.75 \mathrm{C}$ steel. Paper presented before the Am. Soc. Testing Materials, June 1931. 

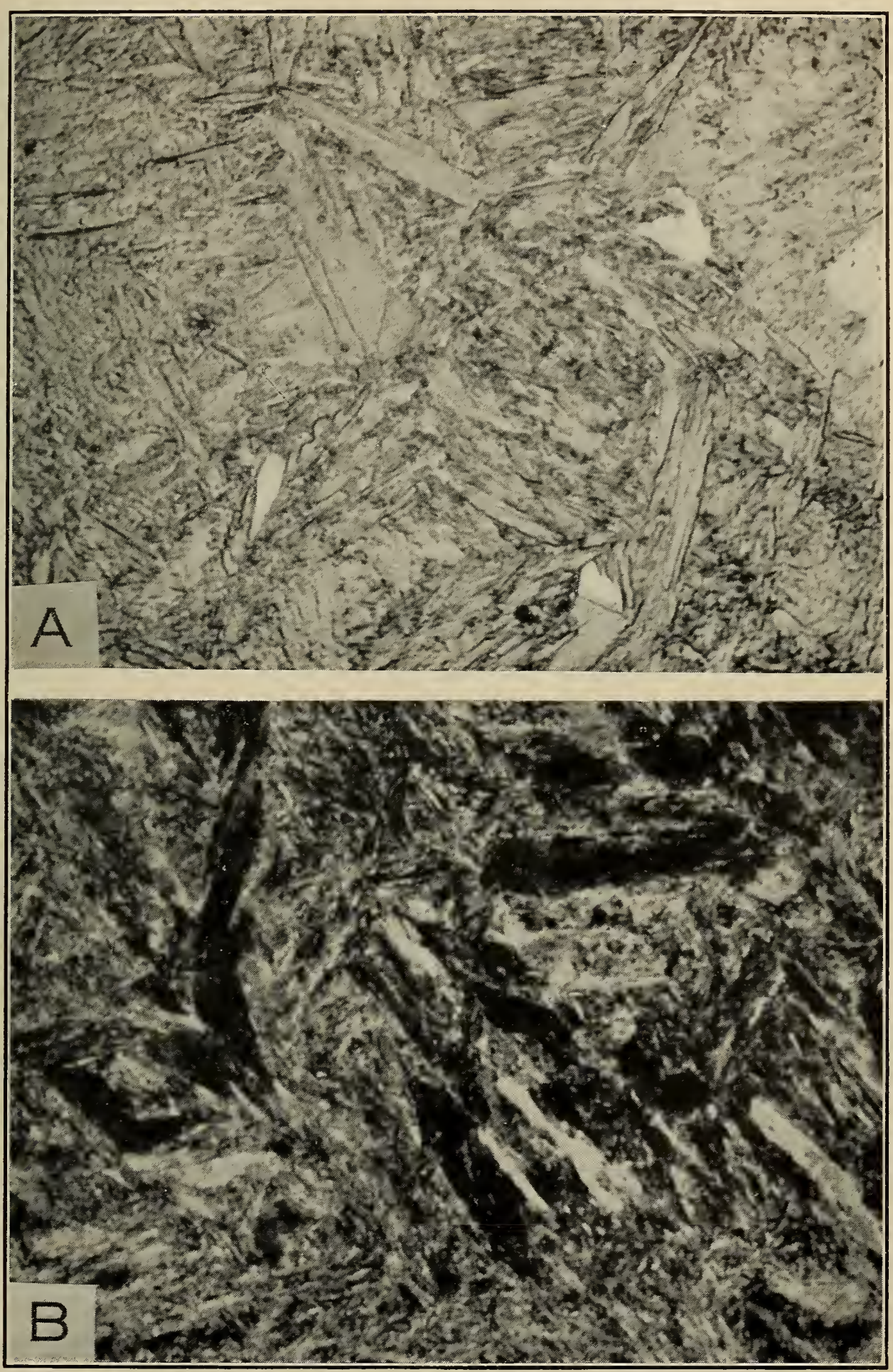

FiguRE 4

$A$, Structure of freshly quenched specimen, $\times 2,000 ; B$, structure of same specimen tempered at $200^{\circ} \mathrm{C}$. for 7 hours, $\times 2,000$. 

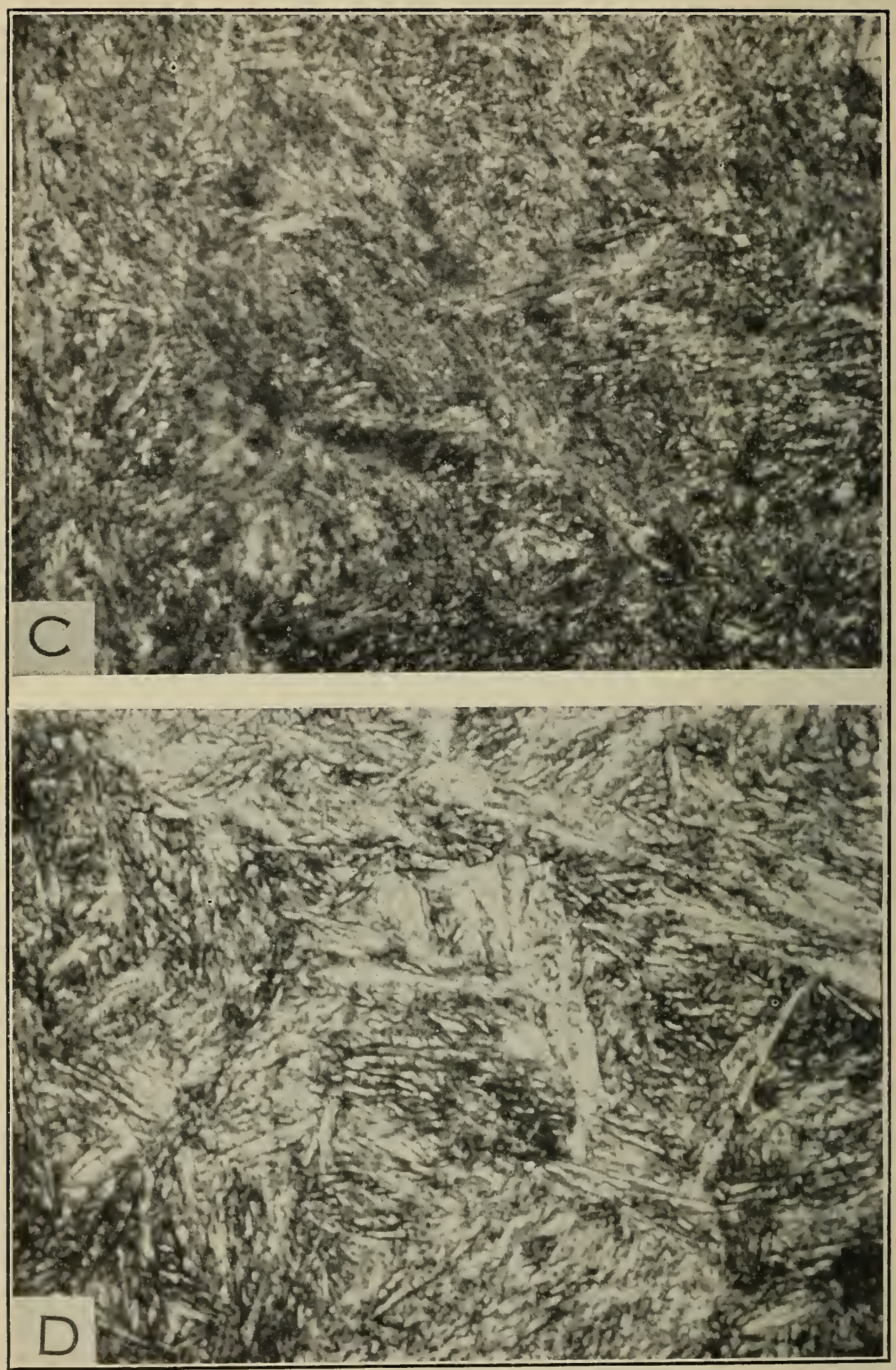

FIGURE 5

$C$, Structure of same specimen tempered at $235^{\circ} \mathrm{C}$. for nearly four hours. $\times 2,000 ; D$, structure of same specimen tempered at $302^{\circ} \mathrm{C}$. for two and one-half hours. $\times 2,0 \mathrm{C} 0$. 


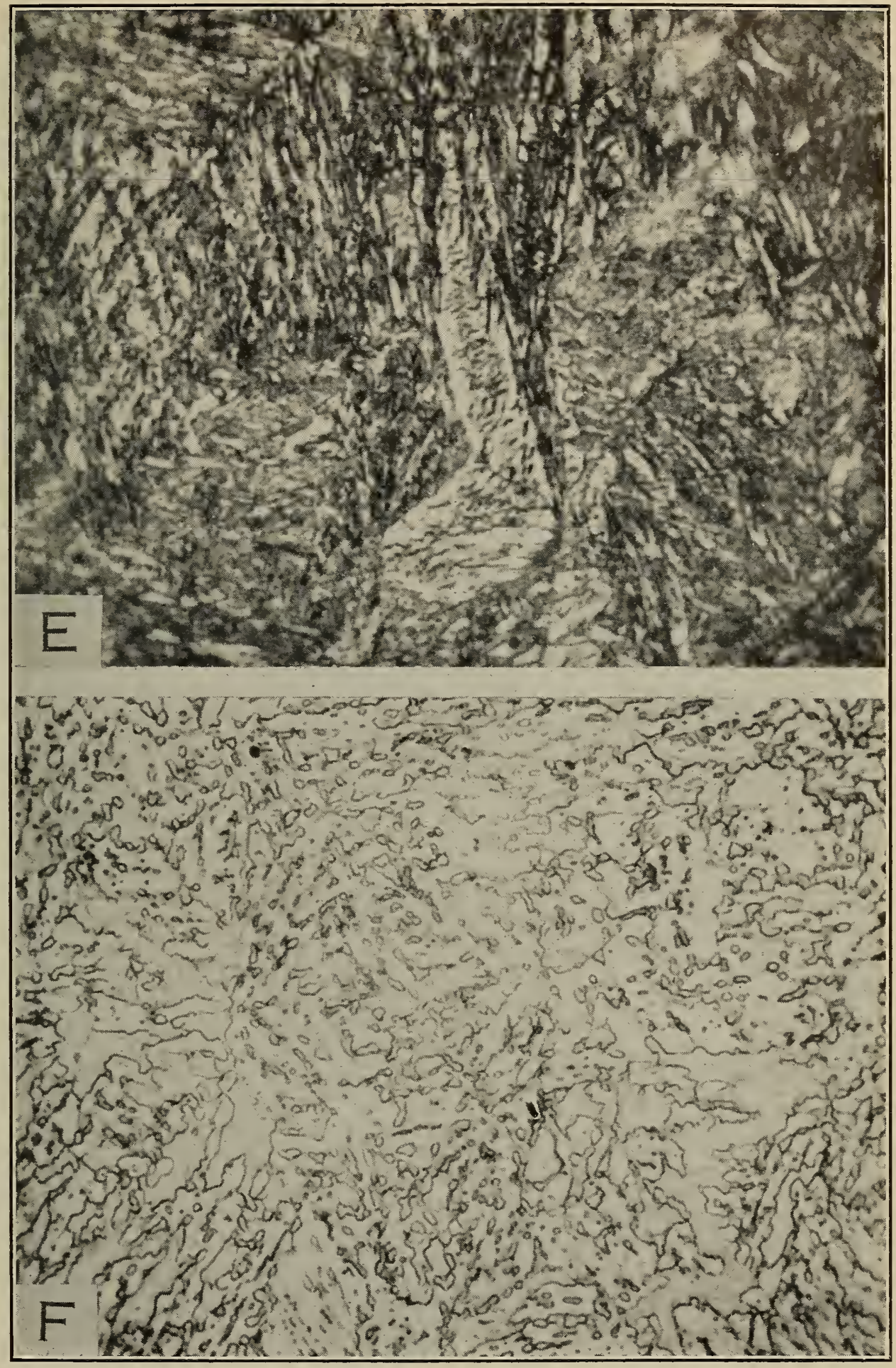

Figure 6

$E$, Structure of same specimen tempered at $400^{\circ}$ C. for two hours. $\times 2,000 ; F$, structure of same specimen tempered at $700^{\circ} \mathrm{C}$. for one hour. $\times 2,000$. 
under the microscope, had an $A_{0}$ transformation, the intensity of which was about half of that of pearlite, whereas specimens containing cementite, spheroidized for various lengths of time, showed a decrease in intensity with growth of particle size.

As a result of these investigations, it is believed that the lack of an $A_{0}$ transformation is due to the absence of carbide in the first stages of the tempering of martensite.

Most metallurgists are agreed that martensite is a supersaturated solid solution of carbon in alpha iron. Jeffries, ${ }^{14}$ discussing the formation of martensite, said:

The transformation in carbon steel is from a solid solution of carbon in gamma iron to a solid solution of carbon in alpha iron. Only one new crystalline phase is formed, the carbide formation being prevented because the time-temperature conditions do not permit of substantial diffusion of carbon.

Heindlhofer and Bain ${ }^{15}$ considered the carbon to be atomically dispersed and the martensite grains to be greatly stressed by their formation. If freshly quenched martensite is considered to contain no carbide and to be in a highly stressed condition, it seems reasonable to attribute the first magnetic change upon heating to $200^{\circ} \mathrm{C}$. to the release of stress, at least in part. At $200^{\circ} \mathrm{C}$. the change, as already noted, requires over six hours for completion. Investigation of tempering at $125^{\circ} \mathrm{C}$. indicates that the same type of change takes place, but that a much greater length of time is required for completion.

Photomicrographs of the material as freshly quenched and after the treatment at $200^{\circ} \mathrm{C}$. (shown in $A$ and $B$, fig. 4), give a clear visual indication that the structure has been altered considerably by the treatment. The original white martensite needles are colored after tempering. The Rockwell hardness also has decreased from C 64 to C 56. Cooling curve 1 and heating curve 2 of Figure 2 indicate that whatever change has taken place in the material, at this stage, has been completed.

Upon reheating to $235^{\circ} \mathrm{C}$. an increase in magnetization took place, which was completed in about 45 minutes. After this the magnetization remained constant for over three hours. This is shown in curve 2 of Figures 2 and 3.

The increase in magnetization indicates that some constituent, previously not contributing to the magnetization, has now become ferromagnetic. Enlund ${ }^{16}$ has stated that austenite tempers at $260^{\circ} \mathrm{C}$. The obvious conclusion is that the retained austenite decomposed at this point, the gamma iron being transformed into the magnetic alpha iron.

Upon cooling to room temperature a slight gradual increase in magnetization was noted. This is presumably the appearance of a carbide transformation.

The miscrostructure of the specimen at this stage, shown in $C$ (fig. 5), indicated that some change had taken place. The structure was fine, being beyond the stage of clear resolution. Some traces of the needles of tempered martensite were still visible. The structure was not that of ordinary troostite as it etched at a somewhat slower

14 Zay Jeffries, A Contribution to the Theory of Hardening and the Constitution of Steel, Trans., Am. Soc. Steel Treating, 13, p. 369, 1928.

${ }_{15} \mathrm{~K}$. Heindlhofer and E. C. Bain, A study of the grain structure of martensite, Transactions, American Society for Steel Treating 18, p. 70, 1930.

16 See footnote 8, p. 443 .

$68723-31-3$ 
rate and had a lighter color than that characteristic of the troostitic range of structures. The hardness was Rockwell C 54, nearly as hard as after treatment at $200^{\circ} \mathrm{C}$.

The specimen was then slowly reheated to approximately $300^{\circ} \mathrm{C}$. This is shown graphically in curve 3, Figure 2. A gradual decrease in magnetization took place upon heating, followed by another decrease upon holding at constant temperature. This latter decrease was complete in about one hour, no further change being noted upon holding for one and one-half hours. The rapid decrease at this stage indicated that a change was taking place within the material, which was effectively decreasing the magnetization of some of the iron.

Upon cooling from $302^{\circ} \mathrm{C}$, the $A_{0}$ transformation was very pronounced as shown in curve 3 of Figure 2. The temperature at which the $A_{0}$ transformation appeared to begin on cooling was approximately $240^{\circ} \mathrm{C}$., instead of $215^{\circ} \mathrm{C}$., as observed for this point in the pearlitic structure of the annealed specimen shown in Figure 1. This confirms the results of the previous investigation ${ }^{17}$ on the influence of carbide particle size, which showed that the $A_{0}$ transformation comes at higher temperatures, the smaller the particle size.

The structure, shown in $D$ (fig. 5) was quite different from that of the preceding specimen. The etching rate was somewhat more rapid and the particles were beginning to resolve. The hardness, Rockwell C 49, was somewhat lower than that of the specimen after the $235^{\circ} \mathrm{C}$. treatment.

When the specimen was heated to $400^{\circ} \mathrm{C}$., the $A_{0}$ transformation was found, but no change in magnetization occurred upon holding at this temperature for two hours, as shown in curve 4 of Figures 2 and 3. Apparently there was no further constitutional change between $300^{\circ} \mathrm{C}$. and the $A_{1}$ transformation, as no magnetic change with time was observed even upon holding the temperature at $700^{\circ} \mathrm{C}$. for one hour.

The microstructure of the specimen held at $400^{\circ} \mathrm{C}$., shown in $E$ (fig. 6) was not greatly different from that of the specimen held at $300^{\circ} \mathrm{C}$. The structure was somewhat coarser and the particle size had increased slightly. The Rockwell hardness had decreased to C 40.

The structure of the specimen held at $700^{\circ} \mathrm{C}$. (shown in $F$, fig. 6) was that of partially spheroidized cementite and the hardness was Rockwell C 12.

All constituents which were stable in the tempering range had been formed at or slightly below $300^{\circ} \mathrm{C}$., any further heating or holding at constant temperatures have apparently no effect in the formation of new constituents. Coagulation of carbide particles took place in the range from $300^{\circ}$ to $700^{\circ} \mathrm{C}$. and gave a continuous series of structures ranging from troostite to speroidized cementite.

\section{SUMMARY}

Properly applied and interpreted, thermomagnetic analysis is capable of revealing constitutional changes in steel which are difficult or impossible to detect by other methods of investigation. This method has been utilized in an investigation of the transformations associated with the tempering of a freshly quenched 0.75 per cent

17 See footnote 13, p. 448. 
carbon steel, and the following phenomena were observed to occur during the process:

1. A pronounced increase in magnetization took place immediately upon the application of heat. After reaching and holding constant at a temperature of $200^{\circ} \mathrm{C}$. this increase continued for approximately six and one-half hours.

2. Another increase in magnetization was noted at about $235^{\circ} \mathrm{C}$. in a specimen previously treated at $200^{\circ} \mathrm{C}$.

3. A decrease in magnetization took place upon holding at a temperature of $300^{\circ} \mathrm{C}$.

4. No change in magnetization with time upon holding at constant temperatures in the range $400^{\circ}$ to $700^{\circ} \mathrm{C}$. was noted.

The explanations of Jeffries, Archer, Sykes, Bain, and others that martensite is a supersaturated solid solution or pseudo solid solution of atomically dispersed carbon in alpha iron, existing only because the conditions of its formation are such as to prevent carbon precipitation is generally accepted as an established fact. That martensite is in a highly stressed condition has also been demonstrated by the X-ray investigations of Heindlhofer, Bain, and others.

With this in mind, the following hypothetical explanation of the tempering of martensite is suggested and is believed to fit the observed phenomena.

The first stage of tempering freshly quenched martensite below $200^{\circ}$ C. resulted in an increase in magnetization which was apparently due to stress release. After this change was completed, no $A_{0}$ or carbide transformation was found. It is conceivable that, during this stage of tempering, the carbon was being precipitated from the solid solution and remained in dispersed form throughout the ferrite. The absence of an $A_{0}$ transformation may be considered to indicate that no carbide had been formed in quantities sufficient to be detected by the magnetic method used.

At approximately $235^{\circ} \mathrm{C}$., the austenite which had been retained during quenching decomposed and in the range, $200^{\circ}$ to $300^{\circ} \mathrm{C}$., carbide formation was progressing. After a period of approximately one hour at the latter temperature the formation of carbide was completed. It is possible that this reaction may be completed at a lower temperature, however, over longer periods of time. At higher temperatures, under the critical range, however, no further magnetization changes with time took place, a fact which suggests that no further constitutional changes occur in steel under these conditions.

\section{ACKNOWLEDGMENT}

Grateful acknowledgment is made to R. L. Sanford, chief of the magnetic measurements section, for the use of the thermomagnetic apparatus and for his kind assistance in the interpretation of results.

WASHington, June 10, 1931. 